\title{
The effect of planned training given to women with preeclamptic pregnancy on oxidative stress and anxiety levels: non-randomised controlled-study
}

emel tasci ${ }^{1}$, serdal ogut ${ }^{2}$, and mehmet özkaya ${ }^{1}$

${ }^{1}$ Süleyman Demirel Üniversitesi

${ }^{2}$ Adnan Menderes Universitesi

April 27, 2021

\begin{abstract}
This study aimed to studying the effects of planned training given to women with preeclamptic pregnancy on stress-anxiety and oxidative stress levels. A non-randomised controlled-study study, carried out in Gynecology and Obstetrics Clinics of Research and Application Hospital of one university. In the study, 28 preeclamptic patients matching the sampling criteria were taken as the experimental group and 22 other preeclamptic patients who also match the sampling criteria constituted the control group. Questionnaire, scale application and laboratory evaluation for the control group were performed only once. In the experimental group, there is a statistically significant difference between the TAS (mmol trolox equ./L) $(\mathrm{t}=-9.71 \mathrm{P}=0.00)$ and the TOS $(\mathrm{lmol} \mathrm{H} 2 \mathrm{O} 2$ equ. $/ \mathrm{L})(\mathrm{t}=6.56 \mathrm{P}=0.00)$ measurements before and after the training and there is a statistically significant difference between the State-Trait Anxiety Inventory $(\mathrm{t}=3.64 \mathrm{P}=0.00)$ before and after the training. It has been determined in the study that the planned training given to the pregnant women who received a diagnosis of preeclampsia has decreased their oxidative stress levels and state anxiety levels.
\end{abstract}

\section{Hosted file}

serdal ogut-manuscript---.pdf available at https://authorea.com/users/410358/articles/519751the-effect-of-planned-training-given-to-women-with-preeclamptic-pregnancy-on-oxidativestress-and-anxiety-levels-non-randomised-controlled-study

\section{Hosted file}

Figure 1.pdf available at https://authorea.com/users/410358/articles/519751-the-effect-ofplanned-training-given-to-women-with-preeclamptic-pregnancy-on-oxidative-stress-andanxiety-levels-non-randomised-controlled-study

\section{Hosted file}

Tables.pdf available at https://authorea.com/users/410358/articles/519751-the-effect-ofplanned-training-given-to-women-with-preeclamptic-pregnancy-on-oxidative-stress-andanxiety-levels-non-randomised-controlled-study 